\title{
ROOT SURFACE STRAIN AND CRACKS DEVELOPMENT BY TWO RECIPROCATING NICKEL TITANIUM FILES
}

\author{
Tarek Medhat Elsewify* and H. M. Elhalaby**
}

\begin{abstract}
Aim: The aim of this study was to determine root surface strain (RSS) developed by two reciprocating NiTi files and the resultant cracks.

Materials and Methods: Thirty mesial roots of mandibular molars were used. Ten roots were prepared using AF Blue R3 Reciprocating One-File System (FBR) (Fanta; ShangHai, China) for the mesiobuccal canal and WaveOne Gold primary (WOG) (Dentsply Tulsa Dental; Tulsa, OK, USA) for the mesiolingual canal. Ten roots were prepared using WOG and ten roots using FBR. An electrical strain gauge was fixed on the root surface connected to a strain amplifier. Maximum strain and time were recorded. Roots were cut transversely to evaluate for cracks.
\end{abstract}

Results: WOG has developed RSS of $(84.16 \pm 52.57)$ and cracks (2/10); FBR has developed RSS of (128.33 \pm 128.55$)$ and cracks (5/10) without statistically significant difference. Preparation time of WOG was $(55.28 \pm 26.24)$ which was statistically significantly less than FBR $(109 \pm 57.3)$.

Conclusion: Both files have developed RSS and cracks during canal shaping.

KEYWORDS: cracks, Fanta Blue R3, reciprocation, root surface strain, WaveOne Gold.

\section{INTRODUCTION}

During endodontic treatment, shaping of the root canals is mandatory to allow for proper disinfection ${ }^{(1)}$. Dentin removal results in weakening of the root structure in addition to the stresses generated during cutting of the dentin structure using endodontic files ${ }^{(2-4)}$.

Capar et al ${ }^{(5)}$ and Liu et al ${ }^{(6)}$ have previously demonstrated the development of dentinal cracks and defects following rotary instrumentation of root canals.

In spite of the great advancement in endodontic files in terms of alloys, design, manufacturing methods, heat treatment and kinematics ${ }^{(7,8)}$, dentinal defects and cracks develop indicating root surface strain build up during instrumentation.

Dentinal defects and cracks will eventually result in root fractures ${ }^{(2)}$. Root fractures will in turn result

\footnotetext{
* Endodontic Department, Faculty of Dentistry, Ain Shams University, Cairo, Egypt
}

** Endodontic Department, Faculty of Dentistry, Assuit University, Assuit, Egypt 
in extraction of the affected teeth. It was previously noted that about $10.9-31 \%$ of the root canal treated teeth are extracted due to vertical root fractures ${ }^{(9-12)}$.

WaveOne Gold (WOG) files are the updated version of WaveOne files (Dentsply Tulsa Dental; Tulsa, OK, USA). They possess different geometry, dimensions and cross-sectional design. They are still used in a reciprocating motion similar to WaveOne files, but they show a parallelogram cross-section with two cutting edges and an off-center design ${ }^{(13)}$. Gold heat-treatment is done through heating followed by slowly cooling of the produced file, unlike M-Wire technology which is done before production $^{(14)}$.

AF Blue R3 Reciprocating One-File System (FBR) (Fanta; ShangHai, China) is manufactured from AF-R wire which improves flexibility according to the manufacturer ${ }^{(15)}$. It shows a rectangular cross section and operates in a reciprocating motion (CCW 150, CW 30).

Development of root surface strain (RSS) and resultant cracks during root canal shaping has not been studied in detail. Therefore, the aim of this study was to compare the RSS and cracks developed during root canal shaping using these two reciprocating files.

\section{MATERIALS AND METHODS:}

\section{Sample selection}

The current study was approved from the Research Ethics Committee of Ain Shams University (Cairo, Egypt), (approval number 08062019). Thirty mesial roots of human mandibular first molars were used in this study. Teeth were examined using dental operating microscope (Zumax, Suzhou New District, China) to exclude roots with open apices, resorptive defects, caries, calcifications and cracks. Teeth with an initial apical diameter greater than a size \#25 K-file were excluded. CBCT images of teeth were obtained to include only the roots showing two separate root canals (Vertucci type IV).

\section{Sample Preparation}

Decoronation was done for all teeth standardizing root length to $12 \mathrm{~mm}$ and patency was checked using a \#10 manual K-file (Mani INC, Tochigi, Japan). The working length was set $0.5 \mathrm{~mm}$ short to the apical foramen.

Roots were coated with a double layer of aluminum foil. Acrylic tubes $12 \mathrm{~mm}$ in height and 20 $\mathrm{mm}$ in diameter were filled with auto-polymerizing resin. Roots with aluminum coating were covered by a separating medium and were embedded centrally in the acrylic tubes. Following setting of the resin, roots were removed. The apical $4 \mathrm{~mm}$ of the acrylic were cut exposing the mesial surface of the root to allow for fixation of the strain gauge. Acrylic tubes were filled with vinyl polysiloxane and then roots were re-embedded in it before setting of the rubber.

\section{Sample Classification}

Roots were randomly divided into three equal groups $(n=10)$. For group A, the mesiobuccal canals were prepared using FBR 0.06/25 and the mesiolingual canal was prepared using WOG primary $0.07 / 25$. Group A was used for evaluation of RSS. For group B, mesiobuccal canals were prepared using WOG and for group C, mesiobuccal canals canals were prepared using FBR. Groups B and C were used for evaluation of crack development.

\section{RSS Measurement}

An electrical strain gauge (KFG02-120-C1-16, Kyowa Dengyo, Tokyo, Japan) was fixed on the mesial surface of the root midway between the buccal and lingual canals using cyanoacrylate. The strain gauge was then connected to a strain amplifier to measure root surface strain during instrumentation. Following stabilization of the strain output, RSS was recorded and root canal shaping was initiated. Instantaneous and maximum strains were recorded. Total time required to reach the working length was recorded by a digital stopwatch (Timex, Middlebury, CT, USA) in seconds. 


\section{Root Canal Shaping}

Both files were operated according to manufacturer's instructions using a 6:1 reduction hand-piece (Reciproc silver, VDW, Germany). "WaveOne All" program was used for the WOG primary files. CCW 150 and CW 30 were used for FBR. Irrigation was performed during instrumentation using $5 \mathrm{~mL}$ of saline (El Nasr Pharmaceutical Chemicals Co., Cairo, Egypt) for each root.

\section{Stereomicroscopic evaluation for crack development}

Roots were cut transversely at 3,6 and $9 \mathrm{~mm}$ from the apex and imaged using stereomicroscope to evaluate for crack development.

\section{Statistical Analysis}

Statistical analysis was performed using statistical package for social sciences (IBM SPSS Statistics for Windows, Version 25.0. Armonk, NY). Significance was analyzed by one-way ANOVA for RSS and preparation time and Chi-squared test for crack development. Data were expressed by mean and standard deviation and $\mathrm{P}<0.05$ was considered as statistically significant.

\section{RESULTS}

WOG has developed RSS of $(84.16 \pm 52.57)$ and cracks (2/10) while FBR has developed RSS of $(128.33 \pm 128.55)$ and cracks $(5 / 10)$ as shown in figure 1. No statistically significant difference was noted between both files. Preparation time of WOG was (55.28 \pm 26.24$)$ which was statistically significantly less than that of FBR $(109 \pm 57.3)$ as shown in table 1.

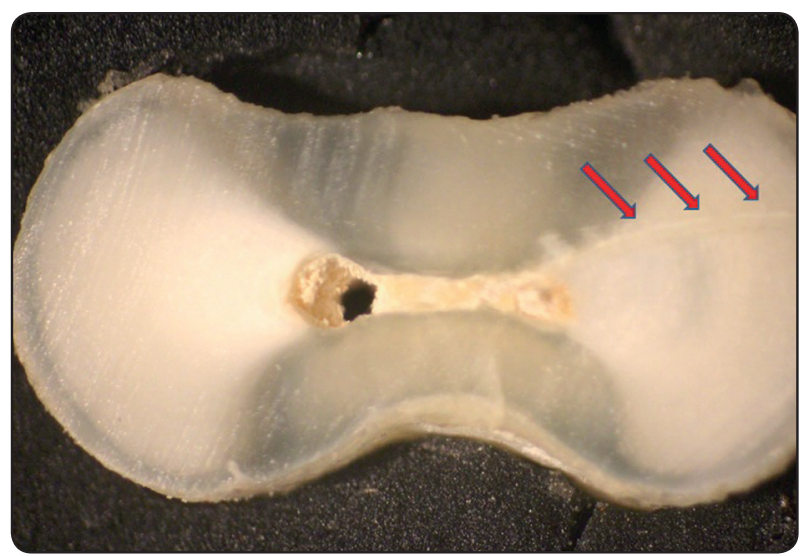

Fig. (1) Stereomicroscopic photograph showing crack developed in group C prepared using FBR (red arrows)

TABLE (1) Mean and standard deviation of maximum RSS and preparation time of WOG and FBR in addition to the presence of cracks.

\begin{tabular}{|c|c|c|c|}
\hline & Maximum RSS (microstrain) & Presence of cracks & Preparation time (seconds) \\
\hline WOG & $84.16 \pm 52.57$ & $2 / 10$ & $55.28 \pm 26.24$ \\
\hline FBR & $128.33 \pm 128.55$ & $5 / 10$ & $109 \pm 57.3$ \\
\hline Statistical test & One-way ANOVA & Chi-squared test & One-way ANOVA \\
\hline P-value & 0.454062 & 0.159599 & 0.043628 \\
\hline
\end{tabular}




\section{DISCUSSION}

As it is not applicable till now to measure the magnitude and direction of internal strain on the dentin walls, RSS was measured where it is a considered as a reflection of the internal strain.

Human mandibular first molars showing two separate root canals (Vertucci type IV) were used in order to standardize experimental conditions, comparing RSS within the same root dentin. The two tested NiTi systems prepared two separate root canals within the same root (group A). This has excluded differences between mechanical properties of dentin from different teeth used in earlier studies ${ }^{(16,17)}$. Although root dentin, speed, torque, motion were standardized, vertical load during mechanical preparation could not be standardized due to inconsistency in the pressure applied by operator. Different specimens were used for the evaluation of crack development (group B for WOG and group C for FBR).

Decoronation was done for all teeth to ensure a straight line access during root canal preparation. Sodium hypochlorite was not used as an irrigant in the current study as it negatively affects the mechanical properties and specifically the elastic behavior of dentin ${ }^{(18)}$. Acrylic tubes were filled with vinyl polysiloxane in order to mimic the physiologic movement of periodontal membrane space during root canal preparation.

The viscoelastic property of dentin allows for deformation under stress followed by recovery which creates strain during mechanical preparation of root canals ${ }^{(16)}$. Results of the current study have shown that the two tested NiTi systems have induced RSS after mechanical preparation of the root canal system without a statistically significant difference between them. This insignificant difference could be simply explained on basis of instrument design. WOG files have greater taper than the FBR, 0.07/25 compared to $0.06 / 25$. This greater taper results in smaller area of contact between the file and the dentin wall which in turn will result in less stresses and
RSS. Another explanation is the shorter preparation time of WOG compared to FBR which results in less stresses as well. In addition to the greater taper and preparation time, the manufacturing alloy might also be another cause as stated earlier by Abou El Nasr \& Abd El Kader ${ }^{(19)}$.

Our results could not be directly compared to earlier studies as none could be found in the literature evaluating WOG or FBR. Jamleh et al (16) compared the RSS induced from Protaper and WaveOne files and found no statistically significant difference between both files as well (416.6 \pm 185.1 and 398.2 \pm 163.8 microstrain respectively). Our results showed much lower microstrain values. This is attributed to the instrumentation motion used, reciprocation compared to continuous rotation. Reciprocation motion results in much less stresses and RSS due to the dis-engagement between the file and dentin allowing for relief of stresses. Liu and $\mathrm{Wu}{ }^{(17)}$ also confirmed this in their study comparing RSS induced from TF adaptive (adaptive reciprocating motion), WaveOne and Protaper Next (continuous rotation) where TF adaptive showed significantly less RSS than the other two files used in continuous rotation motion.

Strained dentin might cause root fractures as stated earlier by Lertickrikaren et al (20). Forcing a finger spreader inside the root canal caused root fracture at 400 microstrain. Saw and Messer (21) reported fracture of maxillary incisors at 200 microstrain. These values are much higher than our results which explain why no root fractures have occurred in our study. Yet cracks have developed following root canal shaping.

WOG has shown less cracks development than FBR. Although non-statistically significant, this is attributed to the less RSS induced by WOG and less preparation time needed.

In agreement with our results, several studies have also shown crack development more in the buccolingual dimension ${ }^{(20,22)}$. Although the widest root dimension is the buccolingual one, all the cracks 
developed in the buccolingual direction (figure 1) ${ }^{(23)}$. Kim et al has shown that stresses were concentrated on the buccal and lingual surfaces of the canal wall using a finite element analysis ${ }^{(24)}$. Therefore, cracks are more likely to develop buccolingually ${ }^{(23,25)}$.

Microorganisms can grow in crack lines causing root canal treatment failure ${ }^{(26)}$. Crack propagation is believed to be the cause of root factures ${ }^{(2,27)}$. Therefore, the etiology of crack development should be better studied ${ }^{(2,3,28)}$.

In conclusion, both files have developed RSS and cracks during root canal shaping without root fractures. WOG was able to shape the root canals faster than FBR. Detailed study of cracks etiology and its relation to RSS is deemed of value.

\section{REFERENCES}

1. Hulsmann M, Peters OA, Dummer PMH. Mechanical preparation of root canals: shaping goals, techniques and means. Endod Top [Internet]. 2005 Mar 1 [cited 2020 Feb 14];10(1):30-76. Available from: http://doi.wiley. com/10.1111/j.1601-1546.2005.00152.x

2. Wilcox LR. The relationship of root canal enlargement to finger-spreader induced vertical root fracture. J Endod [Internet]. 1997 Aug [cited 2020 Feb 14];23(8):533-4. Available from: http://www.ncbi.nlm.nih.gov/pubmed/9587326

3. Sathorn C, Palamara JEA, Messer HH. A comparison of the effects of two canal preparation techniques on root fracture susceptibility and fracture pattern. J Endod [Internet]. 2005 Apr [cited 2020 Feb 14];31(4):283-7. Available from: http://www.ncbi.nlm.nih.gov/pubmed/15793385

4. Zandbiglari T, Davids H, Schäfer E. Influence of instrument taper on the resistance to fracture of endodontically treated roots. Oral Surg Oral Med Oral Pathol Oral Radiol Endod [Internet]. 2006 Jan [cited 2020 Feb 14];101(1):12631. Available from: http://www.ncbi.nlm.nih.gov/ pubmed/16360617

5. Capar ID avu., Arslan H, Akcay M, Uysal B. Effects of ProTaper Universal, ProTaper Next, and HyFlex instruments on crack formation in dentin. J Endod [Internet]. 2014 Sep 1 [cited 2020 Feb 14];40(9):1482-4. Available from: http://www.ncbi.nlm.nih.gov/pubmed/25146038
6. Liu R, Hou BX, Wesselink PR, Wu MK, Shemesh H. The incidence of root microcracks caused by 3 different singlefile systems versus the protaper system. J Endod [Internet]. 2013 Aug [cited 2020 Feb 14];39(8):1054-6. Available from: http://www.ncbi.nlm.nih.gov/pubmed/23880276

7. Bürklein $S$, Tsotsis $P$, Schäfer E. Incidence of dentinal defects after root canal preparation: Reciprocating versus rotary instrumentation. J Endod. 2013 Apr;39(4):501-4.

8. Adorno CG, Yoshioka T, Suda H. Crack initiation on the apical root surface caused by three different nickeltitanium rotary files at different working lengths. J Endod. 2011 Apr;37(4):522-5.

9. Sjögren U, Hägglund B, Sundqvist G, Wing K. Factors affecting the long-term results of endodontic treatment. J Endod. 1990;16(10):498-504.

10. Fuss Z, Lustig J, Tamse A. Prevalence of vertical root fractures in extracted endodontically treated teeth. Int Endod J. 1999 Aug;32(4):283-6.

11. Zadik Y, Sandler V, Bechor R, Salehrabi R. Analysis of factors related to extraction of endodontically treated teeth. Oral Surgery, Oral Med Oral Pathol Oral Radiol Endodontology [Internet]. 2008 Nov [cited 2020 Feb 14];106(5):e31-5. Available from: http://www.ncbi.nlm. nih.gov/pubmed/18718782

12. Touré B, Faye B, Kane AW, Lo CM, Niang B, Boucher Y. Analysis of reasons for extraction of endodontically treated teeth: A prospective study. J Endod. 2011;37(11):1512-5.

13. Gündoğar M, Özyürek T. Cyclic Fatigue Resistance of OneShape, HyFlex EDM, WaveOne Gold, and Reciproc Blue Nickel-titanium Instruments. J Endod [Internet]. 2017 Jul 1 [cited 2020 Feb 14];43(7):1192-6. Available from: http://www.ncbi.nlm.nih.gov/pubmed/28527845

14. Özyürek T. Cyclic Fatigue Resistance of Reciproc, WaveOne, and WaveOne Gold Nickel-Titanium Instruments. J Endod. 2016 Oct 1;42(10):1536-9.

15. Shanghai Fanta Dental Materials Co., Ltd [Internet]. [cited 2020 Feb 14]. Available from: http://fantadental.com/col. jsp?id=127

16. Jamleh A, Komabayashi T, Ebihara A, Nassar M, Watanabe S, Yoshioka T, et al. Root surface strain during canal shaping and its influence on apical microcrack development: A preliminary investigation. Int Endod J. 2015 Dec 1;48(12):1103-11. 
17. Liu W, Wu B. Root Canal Surface Strain and Canal Center Transportation Induced by 3 Different Nickel-Titanium Rotary Instrument Systems. J Endod [Internet]. 2016 Feb 1 [cited 2020 Feb 14];42(2):299-303. Available from: http:// www.ncbi.nlm.nih.gov/pubmed/26686822

18. Kafantari N, Gulabivala K, Georgiou G, Knowles J, $\mathrm{Ng}$ YL. Effect of Heated Sodium Hypochlorite on the Viscoelastic Properties of Dentin Evaluated Using Dynamic Mechanical Analysis. J Endod [Internet]. 2019 Sep 1 [cited 2020 Feb 14];45(9):1155-60. Available from: http://www.ncbi.nlm.nih.gov/pubmed/31326141

19. Abou El Nasr HM, Abd El Kader KG. Dentinal damage and fracture resistance of oval roots prepared with single-file systems using different kinematics. J Endod. 2014;40(6):849-51.

20. Lertchirakarn V, Palamara JEA, Messer HH. Load and strain during lateral condensation and vertical root fracture. J Endod. 1999;25(2):99-104.

21. Saw LH, Messer HH. Root strains associated with different obturation techniques. J Endod [Internet]. 1995 Jun [cited 2020 Feb 14];21(6):314-20. Available from: http://www. ncbi.nlm.nih.gov/pubmed/7673840

22. Von Arx T, Steiner RG, Tay FR. Apical surgery: Endoscopic findings at the resection level of 168 consecutively treated roots. Int Endod J [Internet]. 2011 Apr [cited 2020 Feb 14];44(4):290-302. Available from: http://www.ncbi.nlm. nih.gov/pubmed/21226737
23. Russell AA, Chandler NP, Hauman C, Siddiqui AY, Tompkins GR. The butterfly effect: An investigation of sectioned roots. J Endod. 2013 Feb;39(2):208-10.

24. Kim HC, Lee MH, Yum J, Versluis A, Lee CJ, Kim BM. Potential relationship between design of nickel-titanium rotary instruments and vertical root fracture. J Endod [Internet]. 2010 Jul [cited 2020 Feb 14];36(7):1195-9. Available from: http://www.ncbi.nlm.nih.gov/pubmed/20630298

25. Mannocci F, Pilecki P, Bertelli E, Watson TF. Density of dentinal tubules affects the tensile strength of root dentin. Dent Mater [Internet]. 2004 Mar [cited 2020 Feb 14];20(3):293-6. Available from: http://www.ncbi.nlm. nih.gov/pubmed/15209235

26. Shen Y, Stojicic S, Haapasalo M. Antimicrobial efficacy of chlorhexidine against bacteria in biofilms at different stages of development. J Endod. 2011 May;37(5):657-61.

27. Soros C, Zinelis S, Lambrianidis T, Palaghias G. Spreader load required for vertical root fracture during lateral compaction ex vivo: evaluation of periodontal simulation and fracture load information. Oral Surgery, Oral Med Oral Pathol Oral Radiol Endodontology [Internet]. 2008 Aug [cited $2020 \mathrm{Feb} 14]$;106(2):e64-70. Available from: http://www.ncbi.nlm.nih.gov/pubmed/18554957

28. Bier CAS, Shemesh H, Tanomaru-Filho M, Wesselink PR, Wu MK. The Ability of Different Nickel-Titanium Rotary Instruments To Induce Dentinal Damage During Canal Preparation. J Endod [Internet]. 2009 Feb [cited 2020 Feb 14];35(2):236-8. Available from: http://www.ncbi.nlm. nih.gov/pubmed/19166781 